[Agr. Biol. Chem., Vol. 30, No. 3, p. 203 211, 1966]

\title{
Carbohydrate Metabolism by the Acetic Acid Bacteria
}

\section{Part V. On the Vitamin Requirements for the Growth}

\author{
By Minoru Ameyama and Keiji Kondô \\ Faculty of Agriculture, Shizuoka University \\ Received August 13, 1965
}

\begin{abstract}
Vitamin requirements for the growth of the acetic acid bacteria were investigated extensively on a taxonomical viewpoint and the following new findings were pointed out. Neither Acetobacter nor Intermediate strain required vitamin for the growth.

Gluconobacter required generally pantothenic acid. And some strains belonging to it did moreover somewhat of thiamine, nicotinic acid and $p$-aminobenzoic acid, although there was a difference of requirements between strains even in the same species. Riboflavin, pyridoxine, vitamin $B_{12}$, folic acid, biotin and inositol were unnecessary for the growth of the acetic acid bacteria. A taxonomical division of the acetic acid bacteria based on the vitamin requirements agreed well with that on basis of the oxidative activities for carbohydrates.
\end{abstract}

Using many species and strains of the acetic acid bacteria, the carbohydrate metabolisms of them have been investigated by the authors comparative biochemically. ${ }^{1,2}$ Also in this paper, the vitamin requirements for growth of them were studied on a taxonomical viewpoint.

Until now, the vitamin requirements of the acetic acid bacteria have been reported by the several investigators, ${ }^{3 \sim 9)}$ although on only species by species incoherently without regard to other properties.

Besides, one of the authors' purposes in this paper was to make clear the relationship

1) K. Kondô and M. Ameyama, Bull. Agr. Chem. Soc. Japan, 22, 369 (1958).

2) M. Ameyama, H. Fujisawa and K. Kondô, J. Agr. Chem. Soc. Japan, 39. 427 (1965).

3) L. A. Underkofler, A.C. Bantz and W. H. Peterson, J. Bact., 45, 183 (1943).

4) W. Lisky, W. B. Esselen Jr., B. S. Teper and G. Miller, Food Research, 18, 250 (1953).

5) J. O. Foda and R. H. Vaughn, $J$ Bact., 65, 79 (1953).

6) M. R. R. Rao and J. L. Stokes, J. Bact, 65, 405 (1953).

7) A.N. Hall, G.A. Thomas, K.S. Tiwari and T.K. Walker, Arch. Biochem. Biophys., 46, 485 (1953).

8) C. Rainbow and G.W. Mitson, J. gen. Microbiol., 9, 371 (1953).

9) G. O. Brown and C. Rainbow, J. gen. Microbiol., 15, 61 (1956). between the vitamin requirements and the taxonomical findings based on the oxidative activities for various carbohydrates by the acetic acid bacteria. And the other one was to find out the cause of the physiological and biochemical variations ${ }^{10)}$ of them, for instance on the ketogenic and pigment-producing characteristics, as described in the previous report. ${ }^{2)}$

\section{MATERIALS AND METHODS}

Organisms. Most strains used were supplied by Institute for Fermentation, Osaka, Japan (IFO), and a few isolated from the vinegar workshop and other were also examined. The stock cultures were maintained on $5 \%$ malt agar slants containing $1.5 \%$ of calcium carbonate.

The vitamin-free minimal medium. The composition of the minimal medium used is shown in

10) J. L. Schimwell, Antonie v. Leeuwenhoek., 24, 187 (1958);

R. Steel and T.K. Walker, J. gen. Microbiol, 17, 1445 (1957); J. Inst. Brew., 63, 510 (1957).

J. Tosicí and T.K. Walker, J. Soc. Chem. Ind., 115, 180 (1946).

J. M. Wiame, R. Dothey and R. Harpigny, International Vinegar Congress, The Hauge (1957).

J. L. Schimwell, Antonie v. Leeuwenhoek, 25, 49 (1557),

M. M. R. Rao, Anual Review of Microbiol., 11, 322 (1957).

T. Asai, Recent Progress in Biochem., 6, 1 (1960). 
Table 1. Composition of the Minimal Medium AND THE COMPLETE MEdiUM

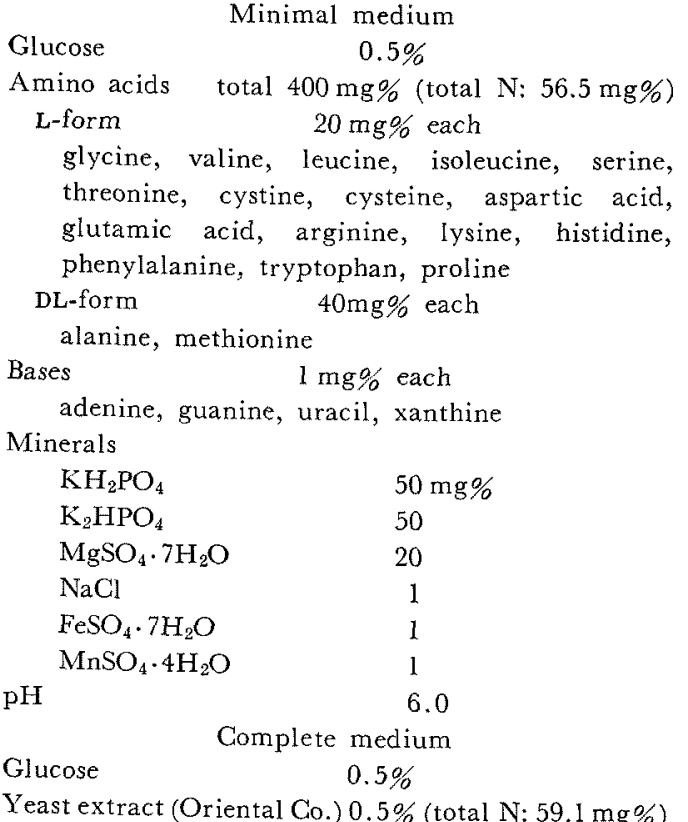

Table I, conforming to the report by Underkofler et al.3)

Vitamins. Ten vitamins examined and their concentrations are shown in Table II. Folic acid, biotin and inositol were used always as a set.

The growth tests were carried out by the omission singly of vitamins from the synthetic medium containing ten vitamins and by the addition singly of them to the minimal medium.

The complete medium composed of $0.5 \%$ glucose and $0.5 \%$ dried yeast extract (Oriental Co.) was used for comparison with the synthetic medium in all experiments.

Inocula were taken from cultures grown stationarily for $48 \mathrm{hrs}$ in the media consisting of $1 \%$ glycerol and $0.5 \%$ dried yeast extract, which were dispensed in $2.5 \mathrm{ml}$ quantities into $8 \mathrm{ml}$ centrifugal tubes and autoclaved. Then the inocula were washed twice centrifugally with sterilized water and suspended in the same one. One drop of the suspension served as inoculum for a test tube of the culturing medium.

The culturing media adjusted to $\mathrm{pH} 6.0$ were dispensed in $6 \mathrm{ml}$ quantities into the test tubes ( $\phi 18 \mathrm{~mm}$, to use for colorimetry) with metal cup and
TABLE II. CONCENTRATION OF VITAMINS IN THE SYNTHETIC MEDIUM

\begin{tabular}{llc}
$\begin{array}{l}\text { Abbre- } \\
\text { viation }\end{array}$ & \multicolumn{1}{c}{ Vitamins } & $\begin{array}{c}\text { Concen- } \\
\text { trations }\end{array}$ \\
$\mathrm{B}_{1}$ & Thiamine-HCl & $40 \mathrm{\gamma} \%$ \\
$\mathrm{~B}_{2}$ & Riboflavin & 40 \\
$\mathrm{NA}$ & Nicotinic acid & 40 \\
$\mathrm{PA}$ & Ca-Pantothenate & 40 \\
$\mathrm{~B}_{6}$ & Pyridoxine-HCl & 80 \\
$\mathrm{PABA}$ & p-Aminobenzoic acid & 10 \\
$\mathrm{~B}_{12}$ & Vitamin $\mathrm{B}_{12}$ & 0.1 \\
$\mathrm{FBI}$ & Folic acid & 0.03 \\
& Biotin & 0.04 \\
Inositol & 0.5
\end{tabular}

autoclaved $\left(1 \mathrm{~kg} / \mathrm{cm}^{2}, 10 \mathrm{~min}.\right)$. The cultures were incubated shaking reciprocally at $30^{\circ} \mathrm{C}$ for 3 days.

Growth was measured as optical density in the Hitachi EBO-B type photometer with a $660 \mathrm{~m} \mu$ filter.

\section{RESULTS}

Reexamination of the minimal medium was carried out using several acetic acid bacteria.

$0.5 \%$ glucose was used as a source of carbon and energy, which was reported to influence on the specific nitrogen requirement. ${ }^{6)}$ This concentration of glucose was convenient to measure the turbidity and to maintain suitable $\mathrm{pH}$ for growth during incubation without any neutralizer.

As a nitrogen source the mixture of amino acids was used. By the way, use of the vitamin-free casamino acid (Nissan Co. and Difco Co.) gave the same results with amino acids mixture. Although tyrosine and hydroxyproline were omitted from the mixture, these were not essential for the growth under the condition mentioned above.

The concentration of the amino acids mixture was adequate between 50 and $150 \mathrm{mg} \%$ as nitrogen, as shown in Fig. 1. By the way, Na-glutamate used as a sole nitrogen source for the growth of $A$. suboxydans var. $\alpha$ was also adequate in the same concentration (see Fig. 1). The concentration of yeast extract in the complete medium was then also adjusted to the same $\mathrm{mg} \%$ of nitrogen. 


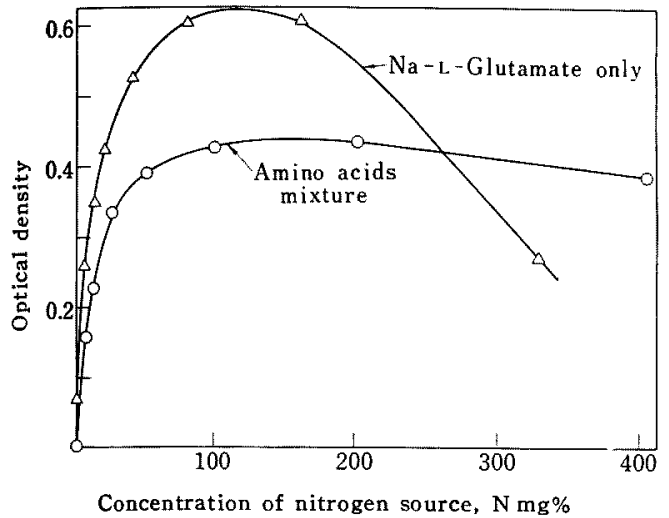

FIG. 1. Relation between the Growth and the Nitrogen Concentration of the Medium.

The medium contained ten vitamins and the substances shown in Table I other than nitrogen source.

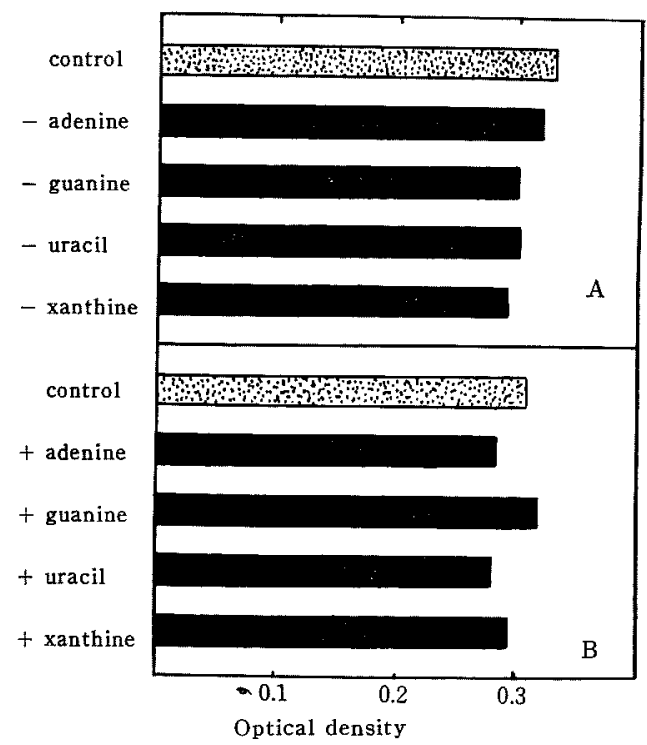

FIG. 2. Effect of the Bases.

A: The basal medium contained ten vitamins and the substances shown in Table I. "-Adenine", "guanine", "- uracil" and "- xanthine" show the growth in the medium without adenine, guanine, uracil and xanthine, respectively.

B: The basal medium consisted of ten vitamins and the substances shown in Table I, without four bases. "+ Adenine", "+ guanine", "+ uracil" and "+ xanthine" show the growth in the medium added adenine, guanine, uracil and xanthine, respectively.
Organic bases used were unnecessary for the growth of all strains (see Fig. 2), although Rao and Stokes ${ }^{6 /}$ and Brown et al. ${ }^{9 /}$ reported that uracil was the essential growth factor of A. rancens, A. melanogenum, A. gluconicum and A. suboxydans.

Minerals used were conformed to the report of Underkofler et al. And yet a simple mixture of $0.02 \% \mathrm{KH}_{2} \mathrm{PO}_{4}, 0.01 \% \quad \mathrm{MgSO}_{4} \cdot 7 \mathrm{H}_{2} \mathrm{O}$ and $2 \% \mathrm{KCl}$ was also sufficient for growth of all strains.

Vitamin requirements. Some instances of vitamin requirements are shown in Fig. 3 and 4. The upper parts in both $A$ and $B$ of the figures indicate the influence of omission singly of each vitamin from the synthetic medium containing ten vitamins. And in the lower parts the effect of addition singly of each vitamin to the minimal medium is shown. As mentioned above, folic acid, biotin and inositol were always treated together in both cases.

As shown in these figures, it was understood that vitamins had not only the inhibitive effect, but also co-multiplicable effect for the growth. This fact, as seen in Fig. 5, was recognized, too. And in this figure, it was indicated that each effective vitamin operated only individually, and that the growth was enough supported by only necessary vitamins, since pantothenic acid plus $p$-aminobenzoic acid supported coefficiently growth of $A$. suboxydans var. $\alpha$ but, even in excess amount, only one of the two did not support the growth sufficiently.

Therefore, in Table III, the results of the omission tests are only expressed.

In order to simplify the presentation of the data and to indicate directly the necessary vitamins, in Table IV, growth is recorded in terms of -.0 and $\div$ For these purposes, on the basis of the growth in the synthetic medium containing ten vitamins, the following arbitrary scale was established and used: for values less than a half, namely required the vitamin; 0 for equal values; and + for 


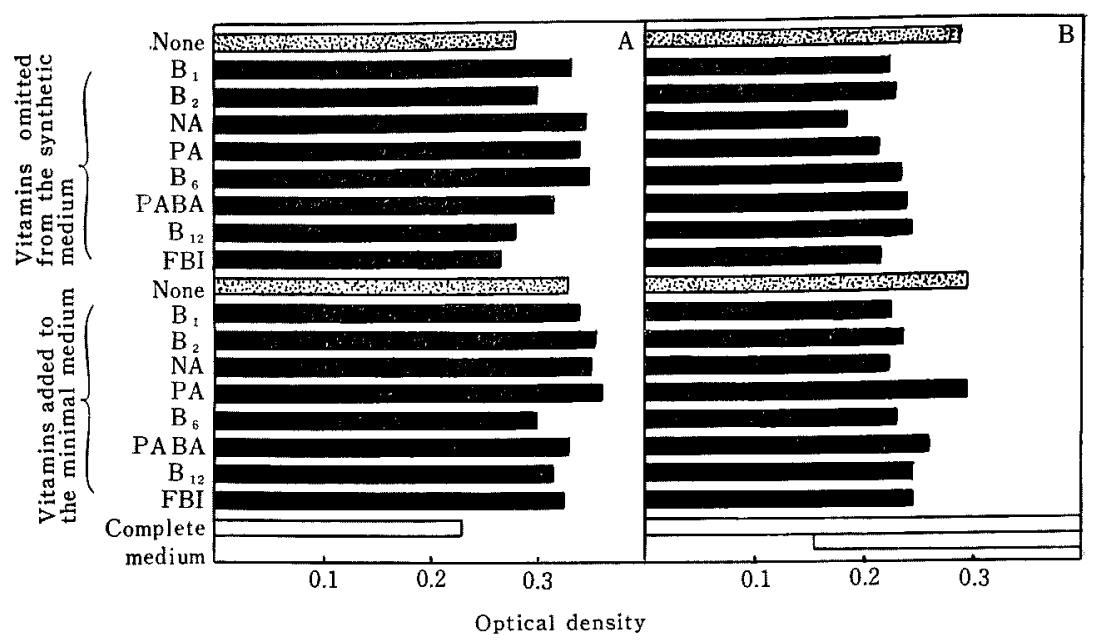

FIG. 3. The Vitamin Requirements of the Acetic Acid Bacteria.

A: A. acetosum var. $\mathrm{EB} 1000$

B: A. aurantium IFO 3246

In the synthetic medium, ten vitamins were added to the minimal medium.

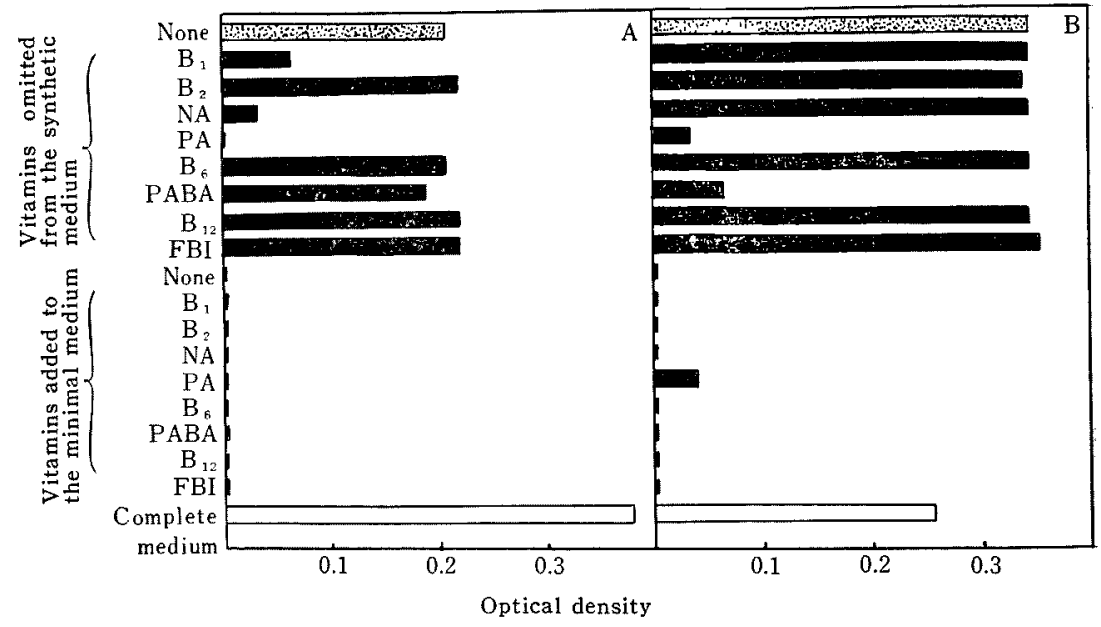

FIG. 4. The Vitamin Requirements of the Acetic Acid Bacteria.

A: A. melanogenum IFO 3292

B: A. industrium IFO 3260

In the synthetic medium, ten vitamins were added to the minimal medium.

values greater than twice growth.

Oxidizabilities for four typical carbohydrates were quoted in Table IV from the previous paper $^{2)}$ studied about many substrates, for reference. These were manometrically meas- ured in a conventional Warburg respirometer at $30^{\circ} \mathrm{C}$ using the resting cells harvested from the malt agar slant cultures containing calcium carbonate. Each vessel contained $1.0 \mathrm{ml}$ ot the cell suspension and $1.5 \mathrm{ml}$ of $\mathrm{m} / 15$ phos- 


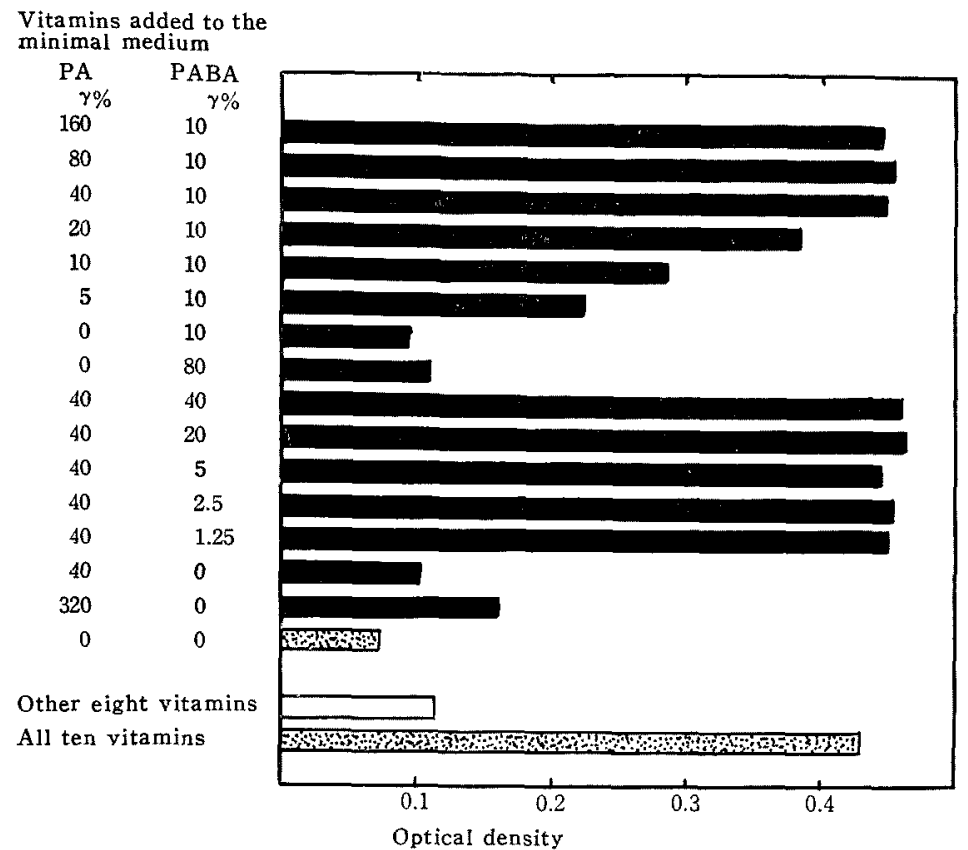

FIG. 5. Vitamin Requirements of A. suboxydans var. $\alpha$ IFO 3254.

Table III. Vitamin Requirements of the ACetic Acid Bacteria

(Optical density $\times 10^{3}$ at $660 \mathrm{~m} \mu$ )

Strains

Acetobacter

A. ascendens

IFO 3299

A. aceti

IFO 3281

A. acetosum var.

EB 1000

A. xylinum var.

EB 1002

A. kützingianum

IFO 3222

A. rancens

IFO 3297

A. acetigenum

IFO 3277

A. albuminosum

IFO 3283

IFO 3284

A. turbidans

IFO 3225

\begin{tabular}{|c|c|c|c|c|c|c|c|c|c|c|}
\hline none & $\mathrm{B}_{1}$ & $\mathrm{~B}_{2}$ & $\mathrm{NA}$ & PA & $\mathrm{B}_{6}$ & PABA & $\mathbf{B}_{12}$ & FBI & all & \\
\hline 028 & 069 & 045 & 037 & 032 & 044 & 048 & 040 & 053 & 048 & 250 \\
\hline 030 & 045 & 048 & 060 & 090 & 042 & 060 & 060 & 048 & 021 & 547 \\
\hline 274 & 325 & 294 & 339 & 333 & 342 & 310 & 275 & 263 & 323 & 229 \\
\hline 313 & 268 & 297 & 295 & 274 & 251 & 283 & 170 & 312 & 264 & 242 \\
\hline 031 & 055 & 028 & 029 & 049 & 078 & 044 & 035 & 056 & 027 & 160 \\
\hline 024 & 020 & 034 & 024 & 016 & 044 & 022 & 019 & 019 & 016 & 262 \\
\hline 071 & 094 & 103 & 077 & 110 & 103 & 095 & 067 & 088 & 098 & 225 \\
\hline 091 & 071 & 090 & 058 & 073 & 088 & 079 & 095 & 085 & 055 & 264 \\
\hline 050 & 051 & 050 & 038 & 058 & 052 & 054 & 046 & 057 & 029 & 360 \\
\hline 240 & 240 & 225 & 237 & 242 & 222 & 223 & 219 & 221 & 209 & 109 \\
\hline
\end{tabular}


TABLE III. (Continued)

Strains

Intermediate type
A. aurantium
IFO 3245
IFO 3246
IFO 3247
G. liquifaciens

Gluconobacter

A. melanogenum

IFO 3292

IFO 3293

A. rubiginosus

IFO 3244

A. dioxyacetonicus

IFO 3272

IFO 3273

IFO 3274

A. orleanens

IFO 3259

A. cerinus
IFO 3262
IFO 3263
IFO 3264

A. cerinus var. ammoniacum IFO 3267

IFO 3268

IFO 3269

A. nonoxy gluconicum

$$
\text { IFO } 3276
$$

A. gluconicum

IFO 3286

A. industrium

$$
\text { IFO } 3260
$$

A. oxydans

IFO 3287

A. capsulatum

IFO 3462

A. albidus

IFO 3251

IFO 3252

A. suboxydans

IFO 3289

IFO 3291

A. suboxydans var. $\alpha$

IFO 3254

IFO 3255 vitamins omitted from the synthetic medium

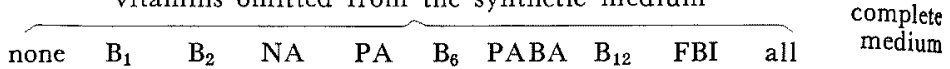

$\begin{array}{lllllllllll}232 & 204 & 211 & 192 & 217 & 183 & 189 & 206 & 215 & 300 & 548 \\ 283 & 219 & 229 & 185 & 210 & 231 & 236 & 240 & 213 & 292 & 598 \\ 255 & 211 & 231 & 206 & 255 & 220 & 250 & 194 & 238 & 315 & 570 \\ & & & & & & & & & & \\ 210 & 199 & 223 & 210 & 229 & 211 & 220 & 224 & 203 & 206 & 410\end{array}$

$\begin{array}{lllllllllll}204 & 064 & 218 & 033 & 000 & 207 & 189 & 219 & 216 & 000 & 375\end{array}$

$\begin{array}{lllllllllll}280 & 303 & 293 & 008 & 006 & 275 & 136 & 273 & 282 & 011 & 555\end{array}$

$\begin{array}{lllllllllll}245 & 055 & 150 & 070 & 015 & 160 & 170 & 245 & 185 & 060 & 660\end{array}$

$\begin{array}{lllllllllll}301 & 252 & 279 & 284 & 025 & 305 & 003 & 280 & 340 & 000 & 365\end{array}$

$\begin{array}{lllllllllll}131 & 143 & 148 & 010 & 000 & 134 & 141 & 114 & 130 & 000 & 155\end{array}$

$\begin{array}{lllllllllll}200 & 170 & 215 & 208 & 008 & 188 & 170 & 195 & 157 & 000 & 201\end{array}$

$\begin{array}{lllllllllll}120 & 098 & 100 & 050 & 003 & 105 & 000 & 109 & 150 & 000 & 395\end{array}$

$\begin{array}{lllllllllll}356 & 299 & 360 & 249 & 017 & 285 & 008 & 335 & 370 & 011 & 230\end{array}$

$\begin{array}{lllllllllll}110 & 149 & 175 & 107 & 012 & 169 & 108 & 142 & 183 & 000 & 280\end{array}$

$\begin{array}{lllllllllll}360 & 343 & 332 & 368 & 000 & 313 & 255 & 370 & 359 & 000 & 406\end{array}$

$\begin{array}{lllllllllll}333 & 070 & 321 & 098 & 010 & 290 & 128 & 330 & 280 & 000 & 450\end{array}$

$\begin{array}{lllllllllll}185 & 210 & 203 & 225 & 015 & 198 & 198 & 205 & 210 & 015 & 290\end{array}$

$\begin{array}{lllllllllll}127 & 134 & 128 & 063 & 020 & 126 & 121 & 101 & 127 & 023 & 450\end{array}$

$\begin{array}{lllllllllll}202 & 245 & 295 & 228 & 012 & 250 & 024 & 280 & 263 & 000 & 415\end{array}$

$\begin{array}{lllllllllll}136 & 145 & 141 & 168 & 011 & 144 & 077 & 147 & 132 & 000 & 218\end{array}$

$\begin{array}{lllllllllll}339 & 340 & 335 & 340 & 033 & 344 & 065 & 340 & 350 & 000 & 255\end{array}$

$\begin{array}{lllllllllll}144 & 167 & 158 & 051 & 009 & 135 & 143 & 151 & 155 & 000 & 318\end{array}$

$\begin{array}{lllllllllll}263 & 179 & 280 & 010 & 016 & 282 & 233 & 274 & 272 & 000 & 350\end{array}$

$\begin{array}{lllllllllll}240 & 250 & 270 & 262 & 020 & 245 & 089 & 295 & 218 & 000 & 369\end{array}$

$\begin{array}{lllllllllll}068 & 038 & 045 & 025 & 008 & 081 & 090 & 057 & 016 & 000 & 039\end{array}$

$\begin{array}{lllllllllll}419 & 325 & 330 & 390 & 012 & 309 & 018 & 346 & 390 & 000 & 478\end{array}$

$\begin{array}{lllllllllll}141 & 128 & 153 & 126 & 001 & 121 & 005 & 126 & 145 & 000 & 265\end{array}$

$\begin{array}{lllllllllll}360 & 335 & 340 & 363 & 012 & 360 & 053 & 368 & 338 & 014 & 413\end{array}$

$\begin{array}{lllllllllll}200 & 209 & 200 & 213 & 009 & 196 & 038 & 204 & 216 & 007 & 106\end{array}$ 
Table IV. Relation Between the Vitamin Requirements and Carbohydrate Oxidizabilities BY THE ACETIC ACID BACTERIA

Growth in*

Strains vitamins omitted from the synthetic

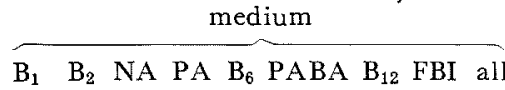

Oxidative activity for ${ }^{\dagger}$

complete medium

arabinose succinate $\mathrm{AcOH}$

EtOH

Acetobacter

A. ascendens

IFO 3299

$\begin{array}{lllllllll}0 & 0 & 0 & 0 & 0 & 0 & 0 & 0 & 0\end{array}$

2

21

2

113

A. aceti

IFO 3281

0

00

$0 \quad 32$

11

49

A. acetosum var.

$\begin{array}{lllllllllll}\mathrm{EB} 1000 & 0 & 0 & 0 & 0 & 0 & 0 & 0 & 0 & 0 & 0\end{array}$

A. xylinum var.

$\begin{array}{lllllllllll}\text { EB } 1002 & 0 & 0 & 0 & 0 & 0 & 0 & 0 & 0 & 0 & 0\end{array}$

A. kützingianum

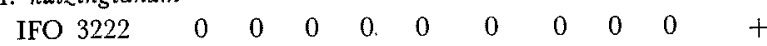

A. rancens

IFO 3297

A. acetigenum

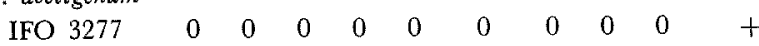

A. albuminosum

$\begin{array}{llllllllll}\text { IFO 3283 } & 0 & 0 & 0 & 0 & 0 & 0 & 0 & 0 & 0 \\ \text { IFO 3284 } & 0 & 0 & 0 & 0 & 0 & 0 & 0 & 0 & 0\end{array}$

A. turbidans

IFO 3225

Intermediate type

A. aurantium

$\begin{array}{llllllllll}\text { AFO } 3245 & 0 & 0 & 0 & 0 & 0 & 0 & 0 & 0 & 0 \\ \text { IFO } 3246 & 0 & 0 & 0 & 0 & 0 & 0 & 0 & 0 & 0 \\ \text { IFO } 3247 & 0 & 0 & 0 & 0 & 0 & 0 & 0 & 0 & 0\end{array}$

G. liquifaciens

$$
\begin{array}{lllllllllll}
25 & 0 & 0 & 0 & 0 & 0 & 0 & 0 & 0 & 0 & +
\end{array}
$$

\section{1}

32

14

27

23

33

37

4

11

8

$$
5
$$

10

Gluconobacter

\begin{tabular}{|c|c|c|c|c|c|c|c|c|c|}
\hline IFO 3292 & - & 0 & - & - & 0 & 0 & 0 & 0 & - \\
\hline IFO 3293 & 0 & 0 & - & - & 0 & 0 & 0 & 0 & - \\
\hline
\end{tabular}

A. melanogenum

A. rubiginosus

IFO 3244

A. dioxyacetonicus

$\begin{array}{lllcccccccc}\text { IFO } 3272 & 0 & 0 & 0 & - & 0 & - & 0 & 0 & - & 0 \\ \text { IFO } 3273 & 0 & 0 & - & - & 0 & 0 & 0 & 0 & - & 0 \\ \text { IFO 3274 } & 0 & 0 & 0 & - & 0 & 0 & 0 & 0 & - & 0\end{array}$

A. orleanens IFO 3259

$00-\quad 0 \quad 0-000-1$

A. cerinus

$\begin{array}{lllllllllll}\text { IFO 3262 } & 0 & 0 & 0 & - & 0 & - & 0 & 0 & - & 0 \\ \text { IFO 3263 } & 0 & 0 & 0 & - & 0 & 0 & 0 & 0 & - & + \\ \text { IFO 3264 } & 0 & 0 & 0 & - & 0 & 0 & 0 & 0 & - & 0\end{array}$ 
TABLE IV. (Continued)

Growth in*

Oxidative activity for ${ }^{\dagger}$

Strains

vitamins omied from the synthetic
medium $\quad \begin{aligned} & \text { complete } \\ & \text { medium }\end{aligned}$

$\mathrm{B}_{1} \mathrm{~B}_{2}$ NA PA $\mathrm{B}_{6}$ PABA B $\mathrm{B}_{12}$ FBI all

arabinose succinate $\mathrm{AcOH} \quad \mathrm{EtOH}$

A. cerinus var. ammoniacum

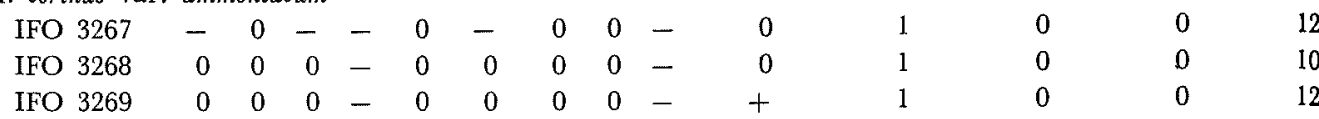

A. nonaxygluconicum

IFO $3276 \quad 0 \quad 0 \quad 0 \quad-\quad 0 \quad-\quad 0 \quad 0 \quad-\quad+$

A. gluconicum

IFO 3286

$0 \quad 0 \quad 0 \quad-$

$\begin{array}{llll}0 & 0 & 0 & -\end{array}$

0

1

$0 \quad 0 \quad 14$

A. industrium

IFO 3260

A. oxydans

IFO 3287

A. capsulatum

IFO 3462

$000-0-000-$

0

1

0

$\begin{array}{ll}0 & 8\end{array}$

A. albidus

IFO 3251

IFO 3252

$0 \quad 0-\quad-\quad 0 \quad 0 \quad 0 \quad 0 \quad+$

$00-\quad 0 \quad 0 \quad 0 \quad 0 \quad 0-0$

2

0

$0 \quad 10$

A. suboxydans

IFO 3289

IFO 3291

$\begin{array}{rrrrrrrrr}0 & 0 & 0 & - & 0 & - & 0 & 0 & - \\ 0 & 0 & - & - & 0 & 0 & 0 & 0 & -\end{array}$

0

0

0

$0 \quad 19$

A. suboxydans var. $\alpha$
IFO 3254
$\begin{array}{llll}0 & 0 & 0 & -\end{array}$
IFO 3255

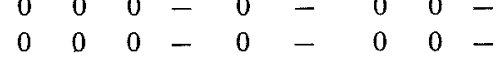
0
0
2
1
* $0=50 \sim 200 \%$ growth compared to that in the synthetic medium containing ten vitamins. $-=<50 \%$. $+=200 \%<$.
$\dagger$ It was represented as the ratio against a value on glucose which was calculated to 10.2 )

0

$0 \quad 14$

phate buffer ( $\mathrm{pH} 6.0$ ) in the main compartment, $0.3 \mathrm{ml}$ of substrate $(30 \mu$ moles $)$ in the side arm and $0.2 \mathrm{ml}$ of $20 \% \mathrm{KOH}$ in the central well. In order to simplify, the activity for the substrates was expressed in the ratio to that for glucose which was calculated to 10 .

\section{DISCUSSION}

The current nomenclatures of "Acetobacter", "Intermediate strains" and "Gluconobacter" have been advanced by Asai et al. ${ }^{11)}$ on basis of the difference on the morphological and

\footnotetext{
11) T. Asai, H. Iizuka and K. Komagata, J. Gen. Appl. Microbiol., 10, 95 (1964).
}

physiological properties, and independently also by the authors on basis of the difference on the oxidative activities for various carbohydrates. ${ }^{21}$ Then, in this paper these nomenclatures were used.

As seen in Table IV, it was found that the vitamin requirements of the acetic acid bacteria were divided into two main parts.

No vitamins used were required for growth of Acetobacter, although it was reported by Foda and Vaughn, ${ }^{5)}$ Hall et al. ${ }^{7)}$ and so on that $A$. rancens, $A$. ascendens, $A$. pasteurianum etc. required several vitamins.

Intermediate strains did not require any vitamins, too. 
Oppositely, Gluconobacter required pantothenic acid in general and moreover some strains did also somewhat of thiamine, nicotinic acid and $p$-aminobenzoic acid.

No strain required riboflavin, pyridoxine, vitamin $B_{12}$, folic acid, biotin and inositol.

While, as shown in Table IV, it has been recognized that Acetobacter oxidized succinate strongly, Intermediate strains, which had distinctively the oxidizability for arabinose, did also it considerably, and, on the contrary, Gluconobacter did not oxidize it entirely.

Thus, it was concluded with great interest that a taxonomical division of the acetic acid bacteria on basis of the vitamin requirements corresponded clearly to that on basis of the oxidative activities for carbohydrates, for example, succinate and acetate.

Besides, in the requirements of thiamine, nicotinic acid and $p$-aminobenzoic acid, the difference between strains belonging to the same species was seen here and there. Such fact had been also observed by Rao and Stokes. ${ }^{6 \prime}$ Authors considered it was a variation as same as mentioned in the previous report.

In many strains the complete medium stimulated growth more than the synthetic medium containing ten vitamins.

Either by reason of existence of unknown effective substances in yeast extract or of inappropriate balance of vitamins or nutrients in the synthetic medium was not concluded hastily. Because, uracil reported by Rao and Stokes and Brown et al. was not recognized in this paper as mentioned above, and acidic effective substance in yeast autolysate reported by Goldman et al. ${ }^{12}$ was not also confirmed yet in yeast extract used by the authors.

There were not also biotin-requiring strains reported by Hall et al."

12) C. L. Goldmann, W. Libsky, M. Mandel and H.N. Little, Can. J. Microbiol., 4, 463 (1958). 